
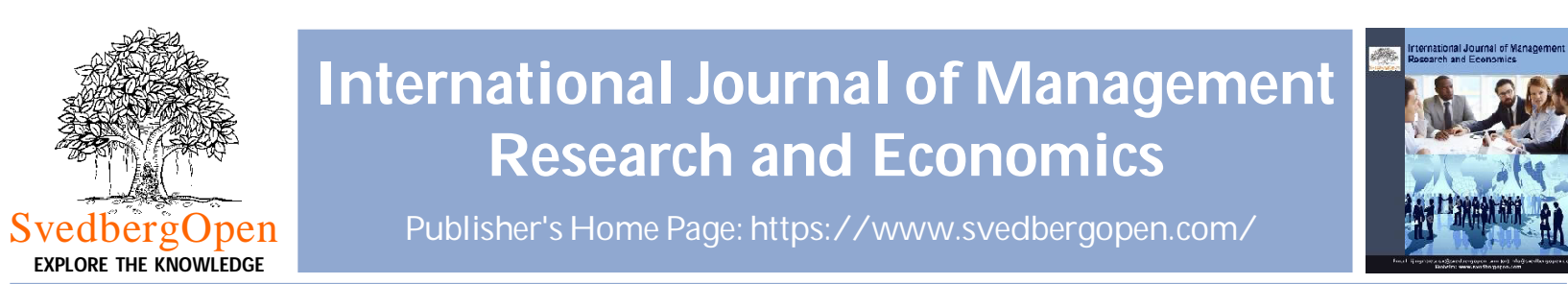

Research Paper

\title{
Electronic banking business in Sub-Saharan Africa: Socio-economic impact and the activities of FinTech ecosystems
}

Olusoji Paul Akinola ${ }^{1^{*}}$

${ }^{1}$ Research Associate, Instituto Universitário de Lisboa (ISCTE-IUL), Business Research Unit (BRU/IUL), Av. Forças Armadas, Lisbon, 1649-026, Portugal. E-mail: sojiakins@yahoo.com

\section{Article Info}

Volume 1, Issue 1, January 2021

Received : 15 November 2020

Accepted : 19 December 2020

Published : 18 January 2021

doi: 10.51483/IJMRE.1.1.2021.27-33

\begin{abstract}
This paper centers on assessing the socio-economic impact of electronic banking business in Sub-Saharan Africa, while critically observing the role that emerging FinTech ecosystems play in deepening economic inclusion and access in developing countries. Extensive related literatures were consulted which were integrated into this new body of knowledge, which has been one of the recommended areas for future research. Research hypothesis were derived to validate relevant findings. This study aim to provide transparency on whether the development of digital payments business and FinTech ecosystems are having a synergistic positive impact or otherwise, on the economic well-being of developing countries. It will also support potential foreign investors and multilateral development agencies on relevant socio-economic factors to note, while expanding into or supporting development in developing countries. The implication of this is for policyholders, multilateral development organizations, investors, donor agencies and governments to be conscious of the real impact and take perceptual measures where and when the need arises.

Keywords: Digital payments, FinTech ecosystems, Developing countries, Economic inclusion, Microeconomic impact

(C) 2021 International Journal of Management Research and Economics. This is an open access article under the CC BY license (https://creativecommons.org/licenses/by/4.0/), which permits unrestricted use, distribution, and reproduction in any medium, provided you give appropriate credit to the original author(s) and the source, provide a link to the Creative Commons license, and indicate if changes were made.
\end{abstract}

\section{Introduction}

Digital payments systems also known as electronic payments systems play a key role in every economy, being the channel through which commercial resources flow from one sector of the economy to the other. Most countries of the world, especially developing countries rely predominantly on cash for most payment transactions. The limitations associated with cash payments such as high cost of cash handling, security, and inefficient flow of commerce has led to the emergence of alternative payment channels such as modern digital payment technologies which have been pioneered by Financial Technology companies also known as 'FinTechs' (Patil et al., 2017). Though cash payments cannot be eliminated however, modern digital technologies have turned traditional cash-based payments systems into a cashless payments system which is more efficient and effective.

The features of digital payments like cost reduction, ease of use, convenience, safety, and speed made digital transactions more acceptable than the cash based traditional payments system (Ravikumar, 2019; Gomber et al., 2017).

The effects of digital business is most visible at the microeconomic level of individual, retail, small-sized firms, wholesale and labor market transactions where there is significant impact on the performance of companies and economic

\footnotetext{
* Corresponding author: Olusoji Paul Akinola, Research Associate, Instituto Universitário de Lisboa (ISCTE-IUL), Business Research Unit (BRU/IUL), Av. Forças Armadas, Lisbon, 1649-026, Portugal. E-mail: sojiakins@yahoo.com
} 
welfare of consumers and workers. Indeed, the gains in efficiency and economic benefits at the microeconomic level exert influence all the way up to the macroeconomic level of GDP and fiscal and monetary phenomena (Heil and Prieger ,2010).

The development of digital payment business especially in the developed countries in recent times has attracted generous scholarly assessment and reviews. While some of the reviews focus on the evolution and role of FinTech firms on the digital payment business development (Teigland et al., 2018). Other researchers focus on the economic benefits of digital payments business (Alt et al., 2018). Kapoor (2016) also evaluated the topic from a human development perspective in terms of economic inclusion and access, specifically financial inclusion. Indeed, digital financial inclusions have been identified as one of the key drivers of the Sustainable Development Goals (SDG's) of the United Nations (Arner et al., 2020). This is because digital financial inclusion services captures the 'unbanked' population which formed about $60 \%$ of adult population in developing countries (Assembly, 2013). Economic exclusion from formal financial services is often a symptom and cause of extreme poverty (Winn, 2016).

Despite the abundant volume of literature on this subject for developed countries, research on developing countries in literature is still limited. The impact of digital payment business on financial inclusion and socio-economic life of individuals, firms, entrepreneurs and government of developing countries have not received abundant assessment in literature (Effah, 2016; Ferran and Salim, 2005).

FinTech (Financial Technology) is an umbrella term for innovative technology-enabled financial services and the business models that accompany those services. In simpler terms, FinTech can be used to describe any innovation that relates to how businesses seek to improve the process, delivery, and use of financial services (Mention, 2019). The concept of the FinTech entrepreneurial ecosystem is a fast growing concept that is now been viewed as a template for economic development (Dapp and Slomka, 2015). The entrepreneurial ecosystem concept represents a new approach to understanding the geography of entrepreneurship through a focus on the high-growth firms, which are responsible for the bulk of all new job creation, and the use of holistic models that draw on fields such as clusters, innovation systems, and social networks (Acs et al., 2017).

The evolution of FinTech enabled digital payments channels such as online, mobile, cards/wallet and other device based channels emanated from developed markets in America, Europe and Asia pacific and it is now spreading to Africa and Latin America. According to Ebeiyamba (2014) the rate of development of these digital channels have been progressively steady in developing countries and not as pronounced when compared to developed countries due to infrastructural and technological challenges. Indeed, Africa as a continent already has 122 million active users of mobile financial services, more than half the global total. Its number of smartphone connections is forecast to double from 315 million in 2015 to 636 million in 2022 - twice the projected number in North America. Over the same period, mobile data traffic across Africa is expected to increase sevenfold (Leke et al., 2018).

\subsection{Statement of problem}

The positive microeconomic impact of digital payments business and FinTech ecosystems especially in developed economies of Western and Northern Europe, America and Asia cannot be overemphasized. These positive impacts are manifested on micro and macroeconomic growth indicators such are GDP, human development index, productivity and employment (Heeks and Bukht, 2018). However, the positive impact of digital business and FinTech ecosystems in developing countries of Africa and Latin America have been under-researched (Vujica Lazovic and Tamara Durickovic, 2010; Heeks and Bukht, 2018).

\section{Literature review}

The last two decades have witnessed advancements in information and communication technology which have empowered societies and changed the entire business landscape with new business and service models (Teigland et al., 2018). Over the last decade, digital technology has led to transformation at all levels from individuals, organizations, government and the entire society at large. An understanding of the impacts of digital business and its varied business models on socio-economic development and growth and how it will impact change is still currently under study especially in the developed world. This however, has not been extensively researched in the developing economies (Kamel, 2008; Datta, 2011). The growth in the development of digital business products or services have been facilitated by increased adoption of the internet, data affordability and availability of smart phones and technology ecosystems such as FinTech ecosystems. 


\subsection{Defining digital payment business}

Over the last four decades, the dominant perception is that digital or ICT strategy is a functional enabler of business strategy. In other words it suggests that IT strategy merely supports an underlying business strategy. This view point was also reinforced by (Venkatraman et al., 1993) that business strategy directed IT strategy despite plethora of calls for recognizing the impact of IT strategy to shape business strategy and transforming business strategy and business scope. The school of thought that digital strategy is subordinate to business strategy persisted for a while and was reflected in a number of studies including studies in business process design, digital outsourcing, IT transformation, inter and intra company systems, business value of IT, and so on (Chan and Reich, 2007; Hirschheim and Sabherwal, 2001; Luftman and Brier, 1999).

However, the last two decades have witnessed impressive improvements in digital and communications technology, the internet and world wide web, mobile computing, wireless technology, artificial intelligence, Internet of things, and so on. Interestingly, this era has seen firms taking advantage of these novel improvements in digital infrastructures to adapt their business infrastructure to the emerging digital business order. These digital technologies are fundamentally reshaping traditional business strategies, global business process management (Kohli and Grover, 2008; Rai et al., 2012) and transforming the structure of social relationships both in the consumer and enterprise states with social media and social networking platforms (Susarla et al., 2012). Digital technologies are also breaking new grounds by creating entirely new industries and disrupting existing industries across borders and boundaries (Burgelmann and Grove, 2007). Bharadwaj et al. (2013) defines digital business as a business which uses technology to formulate and execute business objectives leveraging digital resources to create differential value.

\subsection{Defining FinTech entrepreneurial ecosystems}

FinTech is recognized as one of the most important innovations in the financial industry and is evolving at a rapid speed, driven in part by the sharing economy, favorable regulation, and information technology. FinTech is reshaping the financial industry landscape by disintermediating financial services and creating new frontiers of digital payments to drive economic growth (FinTech, 2015). In recognition of the catalytic capacity of FinTech entrepreneurial ecosystem to stimulate economic growth, governments all over the world have been giving support to FinTech ecosystems since the 2008 financial crisis (FinTech, 2015).

\subsection{Nexus between digital business and FinTech entrepreneurial ecosystem}

The role of FinTech ecosystems in the development of digital business is best expressed in recent innovations and advancements in the digital payments and digital financial services landscape. FinTech startups are indeed challenging the status quo with innovative propositions, trying to disintermediate financial institutions from their traditional function of payment service providers (Omarini, 2018). According to Mellon (2015), consumer, retail and corporate payments FinTechs include mobile wallets, e-commerce, peer-to-peer (P2P) mobile payments, foreign exchange and remittances, payments, and digital currency solutions. Approaches to digital payments services includes but not limited to: electronic payments, e-commerce/internet payments, charging to a phone bill, near field communication (NFC), barcode or QR code, a credit card on mobile websites, a mobile phone card reader, and direct mobile payment without using credit card companies such as mobile USSD solution and mobile apps (Li, 2016).

The socio-economic impact of digital business and the contribution of FinTech ecosystems to the economic wellbeing of developed economies has been well documented in literature. Indeed there has been sustained focus in terms of investment and resources in the FinTech space in Europe, Asia and America (Mention, 2019; Lee and Shin, 2018). Six years ago, the FinTech industry attracted $\$ 12.2$ bn in investment (Accenture, 2016); in 2018, the top 250 FinTech firms collectively raised more than $\$ 31.85$ bn (CBInsights, 2018). KPMG's (2018) FinTech pulse report stated that global FinTech investment increased from $\$ 50.8$ bn in 2017 to $\$ 111.8$ bn in 2018 , more than doubling, with an unprecedented number of deals through multiple channels.

\subsection{Research objective}

The specific objective of this research study is to evaluate the effects of digital payments or cashless business and FinTech entrepreneurial ecosystems on the microeconomic life of selected developing countries, by studying the direct and indirect impacts on consumers, income levels, the informal economy, small businesses and financial institutions. A secondary objective of this study is to explore the implications for economic inclusion and access in these countries in line with some specific themes of the SDG's of the United Nations. This study also intends to discover research gaps and opportunities for future study with reference to digital payments business and the FinTech entrepreneurial ecosystems development in developing countries. The outcome of this study will serve as a guide to investors, multilateral development agencies, practitioners and regulators in the digital and FinTech entrepreneurial space. 


\subsection{Research hypotheses}

The following hypotheses were generated:

RH1: Digital payments business development is positively related to the existence of FinTech entrepreneurial ecosystems.

RH2: Digital payments business has positive effects on cost optimization and revenue maximization for financial institutions in developing countries.

RH3: Digital payments business has a positive effect on micro small and medium size businesses in developing countries.

RH4: FinTech entrepreneurial ecosystem has positive effect on economic inclusion for the 'unbanked' population (i.e., population without bank accounts or access to financial services).

\section{Research methods}

\subsection{Methodology}

This study will adopt a combination of qualitative and quantitative data collection methods. The real impact on financial inclusion, consumer experience, small and medium sized companies, FinTechs and financial institutions as either positively or negatively influenced is well converged via data analysis. While observations, surveys and personal interviews will be used to analyze the subjective factors that may not be expressed through data.

\subsection{Research scope}

Listed countries including, Nigeria, Ghana and Kenya, where there have been strong development of digital business and FinTech ecosystems will be sampled with frequent visits to analyze recent developments (Leke et al., 2018). A comprehensive questionnaire will be administered to carefully sampled stakeholders; digital business representatives, financial institutions representatives, FinTech ecosystems representatives, individuals and owners of small businesses to validate our arguments and generate new discoveries.

Collected data will be analyzed via statistical packages to identify patterns, draw inferences and conclusions.

\section{Expected outcome}

The value addition of digital payments business and FinTech entrepreneurial ecosystems as drivers of economic growth cannot be discounted considering the immediate and long-term socio-economic impact that they have on the society. However, it is important to have a deep dive and really validate the real value added that they bring to the economy and economic agents when compared to traditional cash-based payments business channels and their impact to their societies.

\subsection{Traditional financial institutions}

In Greenspan (2007) 'The age of based on studies conducted by (Sumathy and Vipin, 2017) in India, six motivational factors: security, ease of use, availability, convenience, intention to use, complexity of the technology were key factors influencing the use of the Point of Sales (POS) terminals in India. The positive effect on the consumer ranges from convenience to executing transaction from comfort of homes, one stop shopping, more varieties, reliability, reporting and ability to do transactions anytime and anywhere. A very important negative effect is the sense of lack of security or compromise of access codes. Despite these negative effects the positive features of digital payments attract many consumers, especially those in the middle-income level who frequently make use of digital payments (Casado-Aranda et al., 2018).

\subsection{Effect on micro and small scale businesses}

There is no generally accepted definition of micro and small scale businesses as changes in price level and technological advancement typically affects its definition. All over the world, the functional factor often 'used as criteria for defining business size are turnover, gross output and employment (Safiriyu and Njogo, 2012). Other factors such as financial strength, relative size, value, initial capital outlay, and type of industry are also used (Carpenter and Petersen, 2002). Hence, micro and small scale enterprises have different meanings from country to country. SME's are often regarded as the engine room of growth in many economies and very instrumental in promoting private sector development and alleviating poverty (Ebeiyamba, 2014). Adebiyi (2013) also noted that SME's creates competitive market pressure, while they also play important role as sub-contractors in the downsizing, privatization and restructuring of large enterprises.

In developing countries, SME's do not have the sophistication, class and literacy when compared to developed countries. Ogu (2011) pointed out the high level of illiteracy among small business owners in Africa makes penetration 
of digital payments difficult. Also, (Ebeiyamba, 2014) also suggested that a good number of SME's studied in Nigeria had no bank accounts, hence making them financially excluded. However, the adoption of digital payment business by SME's is not an end in itself but should be viewed as a means towards an end. A holistic understanding of how SME's are formed, its underlying regulatory framework and how SME's operate in the developing economies needs to be evaluated (Taylor and Murphy, 2004).

\section{Conclusion}

The development of digital payments business and FinTech ecosystems in developing countries requires the attention of researchers to create some level of transparency to venture capitalist, and other tech savvy foreign investors and add to the body of knowledge. It is also important to stress that the increasing literature on the 'digital payments business revolution' especially with regards to developing economies is not on itself exhaustive as many aspect need to be further evaluated.

However, this study will not be the final word on the matter, as further qualitative and quantitative research still needs to be conducted to validate the expected outcome. This study stresses the importance and economic benefits that digitalization and entrepreneurial ecosystems brings to developing countries. However, to have sustainable digital business value proposition in different countries, the resulting effects needs to be properly analyzed and suggested solutions need to be proposed to the appropriate government authorities, regulators and policyholders for proactive measures in favor of the economy.

\section{References}

Accenture (2016). Fintech and the evolving landscape: landing points for the industry. Accenture. https:// www.accenture.com/t20161011T031409Z__w__/pl-en/_acnmedia/PDF-15/Accenture-Fintech-EvolvingLandscape.pdf

Acs, Z.J., Stam, E., Audretsch, D.B. and O'Connor, A. (2017). The lineages of the entrepreneurial ecosystem approach. Small Business Economics. 49(1), 1-10.

Adebiyi S.O. (2020). Why small business fail. available at http://proshaeng.com/news/12330 accessed 5th Feb, 2020.

Alt, R., Beck, R. and Smits, M.T. (2018). FinTech and the transformation of the financial industry. Electron. Mark. 28(3), 235-243.

Arner, D.W., Buckley, R.P., Zetzsche, D.A. (2020). Sustainability, FinTech and financial inclusion. Eur Bus Org Law Rev. 21, 7-35 . https://doi.org/10.1007/s40804-020-00183-y

Assembly, U.G. (2013). A life of dignity for all: accelerating progress towards the millennium development goals and advancing the United.

Bharadwaj, A., El Sawy, O.A., Pavlou, P.A. and Venkatraman, N. (2013). Digital business strategy: toward a next generation of insights. MIS quarterly. 471-482.

Burgelman, R.A. and Grove, A.S. (2007). Crossboundary disruptors: powerful interindustry entrepreneurial change agents. Strategic Entrepreneurship Journal. 1(34), 315-327.

Carpenter, R.E. and Petersen, B.C. (2002). Is the growth of small firms constrained by internal finance?. Review of Economics and statistics. 84(2), 298-309.

Casado-Aranda, L.A., Liébana-Cabanillas, F. and Sánchez-Fernández, J. (2018). A neuropsychological study on how consumers process risky and secure E-payments. Journal of Interactive Marketing, 43, 151-164.

CBInsights (2018). The Fintech 250: The top fintech startups of 2018. Research Briefs. October 22. https:// www.cbinsights.com/research/fintech-250-startups-most-promising/

Chan, Y. and Reich, B. (2007). IT alignment: what have we learned?. J Inf Technol. 22, 297-315. https://doi.org/10.1057/ palgrave.jit.2000109.

Credit Suisse, WWF, McKinsey and Company (2014). Conservation fi-nance: moving beyond donor funding toward an investor-driven approach. CS, WWF, and McKinsey, Zurich.

Dapp, T. and Slomka, L. (2015). Fintech reloaded-traditional banks as digital ecosystems. Publication of the German original. pp. 261-274.

Datta, P. (2011). A preliminary study of ecommerce adoption in developing countries. Information Systems Journal, 21(1),3-32. 
Ebeiyamba Oluchukwu, J. (2014). Effect of cashless economy on micro and small scale businesses in Nigeria. European Journal of Business and Management. 6(1), 101-106.

Effah, J. (2016). Institutional effects on e-payment entrepreneurship in a developing country: enablers and constraints. Information Technology for Development. 10.1080/02681102.2013.859115

Ferran, C. and Salim, R. (2005). Electronic business in developing countries: the digitalization of bad practices. In Electronic business in developing countries: Opportunities and challenges (pp. 1-35). IGI Global.

FinTech, H. (2015). The future of finance: The socialization of finance. Available at http://hollandFinTech.com/thefuture-of-finance-the-socialization-of-finance/.

Gomber, P., Koch, J. A. and Siering, M. (2017). Digital finance and fintech: current research and future research directions. Journal of Business Economics, 67(5), 537-580.

Greenspan, A. (2007). The roots of mortgage crisis. The Wall Street Journal, 12. P.A19.

Heeks, R., and Bukht, R. (2018). Digital economy policy in developing countries.

Hirschheim, R. and Sabherwal, R. (2001). Detours in the path toward strategic information systems alignment. California Management Review, 44(1), 87-108.

Heil, D. and Prieger, J.E. (2010). The macroeconomic impacts of e-business on the economy. In Encyclopedia of Ebusiness development and management in the global economy. 1-11. IGI Global.

Kamel, S.H. (2008). May. The role of ICT in building a knowledge-based society. In Proceedings of the Egyptian German Think Tank Conference Towards an Innovative Approach to Think Tanks Management. Cairo, Egypt. June.

Kapoor, R. (2016). How india can be a cashless economy. The Economic Times.

Kohli, R. and Grover, V. (2008). Business value of IT: An essay on expanding research directions to keep up with the times. Journal of the Association for Information Systems, 9(1), 1.

KPMG. (2018). The pulse of fintech 2018: Global report on fintech investment trends. KPMG, April. https://home.kpmg/ au/en/home/insights/2017/04/pulse-of-fintech.html

Lee, I. and Shin, Y.J. (2018). Fintech: ecosystem, business models, investment decisions, and challenges. Business Horizons. 61(1), 35-46.

Leke, A., Chironga, M. and Desvaux, G. (2018). Africa's business revolution: How to succeed in the world's next big growth market. Harvard Business Press.

Li, E. and Li, J. (2016). Information security challenges in the new era of Fintech. Proceeding of ICEB.

Luftman, J. and Brier, T. (1999). Achieving and sustaining business-IT alignment. California Management Review. 42(1), 109-122.

Mellon, B.N.Y. (2015). Innovation in payments: The future is FinTech. The Bank of Newyork. Available at https:// www.bnymellon.com/_global-assets/pdf/our-thinking/innovation-in-payments-the-future-is-FinTech.pdf

Mention, A.L. (2019). The future of Fintech. Research-Technology Management. 62(4), 59-63. DOI: 10.1080/ 08956308.2019.1613123.

Ogu, I.A. (2011). Faulting CBN's rationale for daily cash withdrawal limits. http://mobile.saharareporters.com/article/ faulting-cbn's-rationale-daily-cash-withdrawal-limts-ikechukwu-ogu

Omarini, A.E. (2018). The Retail Bank of Tomorrow: A Platform for Interactions and Financial Services. Conceptual and Managerial Challenges. Research in Economics and Management (REM), 3(2), 110-133.

Patil, P.P., Dwivedi, Y.K. and Rana, N.P. (2017). Digital payments adoption: an analysis of literature. In: Kar, A., et al. (eds.) Digital Nations - Smart Cities, Innovation, and Sustainability, I3E 2017. Lecture Notes in Computer Science, vol. 10595, 61-70. Springer, Cham (2017). https://doi.org/10.1007/978-3-319-68557-1_7

Rai, A., Pavlou, P.A., Im, G. and Du, S. (2012). Interfirm IT capability profiles and communications for cocreating relational value: evidence from the logistics industry. MIS Quarterly, 233-262.

Ravikumar, T. (2019). Digital financial inclusion: a payoff of financial technology and digital finance uprising in India.

Taylor, M. and Murphy, A. (2004). SMEs and ebusiness. Journal of Small Business and Enterprise Development.

Safiriyu, A.M. and Njogo, B.O. (2012). Impact of small and medium scale enterprises in the generation of employment in Lagos State. Kuwait Chapter of the Arabian Journal of Business and Management Review. 1(11), 107. 
Sumathy, M. and Vipin, K.P. (2017). Digital payment systems: Perception and concerns among urban consumers. IJAR. 3(6), 1118-1122.

Susarla, A., Oh, J.H. and Tan, Y. (2012). Social networks and the diffusion of user-generated content: Evidence from YouTube. Information Systems Research, 23(1), 23-41.

Teigland, R., Siri, S., Larsson, A., Puertas, A.M. and Bogusz, C.I. (2018). The rise and development of FinTech: Accounts of disruption from Sweden and Beyond. Routledge: London, UK. Available at SSRN: https://ssrn.com/ abstract $=3140680$

Venkatraman, N., Henderson, J.C. and Oldach, S. (1993). Continuous strategic alignment: Exploiting information technology capabilities for competitive success. European Management Journal. 11(2), 139-149.

Vujica Lazovic and Tamara Durickovic (2010). Economic analysis of the Egovernment development in Montenegro. Montenegrin Journal of Economics, Economic Laboratory for Transition Research (ELIT), 6(12), 99-106.

Winn, J.K. (2016). Mobile payments and financial inclusion: Kenya, Brazil, and India as case studies. In Research Handbook on Electronic Commerce Law. Edward Elgar Publishing.

Cite this article as: Olusoji Paul A kinola (2021). Electronic banking business in Sub-Saharan A frica: Socio-economic impact and theactivities of FinTech ecosystems. International J ournal of M anagement Research and Economics. 1(1), 27-33. doi: 10.51483/ IJMRE.1.1.2021.27-33. 